\title{
Contrived Making Do As Rhetorical Practice in Outdoor Recreation
}

\author{
Samantha Senda-Cook* \\ Creighton University, Omaha, NE, United States
}

Descriptors such as "hideous," "the worst," "terrible," and "thrashed" are not the words that most people want to associated with their "usual." For many outdoor recreators, though, these are things that they learn to live with. But why? Why do they continue to engage in practices that produce these results? I argue that such activities constitute what I call contrived making do and that they function as rhetorical practices that construct identities and parts of the outdoor recreation subculture in the following three ways: controlling the controllable, walking the edge, and reframing the experience.

OPEN ACCESS

Edited by:

Tracylee Clarke,

California State University, Channel Islands, United States

Reviewed by:

Carlos Anthony Tarin, University of Texas at El Paso,

United States

Kate Maddalena,

University of North Carolina at Wilmington, United States

Deborah Cox Callister, University of San Francisco, United States

*Correspondence: Samantha Senda-Cook samanthasenda-cook@ creighton.edu

Specialty section: This article was submitted to Science and Environmental Communication,

a section of the journal Frontiers in Communication

Received: 26 July 2017 Accepted: 29 September 2017 Published: 19 October 2017

Citation:

Senda-Cook S (2017) Contrived Making Do As Rhetorical Practice in Outdoor Recreation. Front. Commun. 2:15. doi: 10.3389/fcomm.2017.00015
Contrived making do refers to creating or seeking out situations that necessitate getting by in a physical and/or cultural sense, implying both difficult circumstances and the creativity and wherewithal to figure out improvised solutions. Making do, in this context, depends on privilege, risk - the willingness to take normalized risks and framing risk in culturally expected ways - and voluntarily surrendering some control. This analysis adds nuance and richness to Michel de Certeau's concept of making do. Whereas de Certeau conceptualized making do as a coping mechanism for marginalized groups, my project illuminates the role that risk plays in making do by showing how a comparatively privileged group of people seek out such experiences. In doing so, this study builds on environmental communication scholarship about risk by demonstrating that mere carelessness may not be the only source of injuries in national parks.

Keywords: making do, rhetorical practices, risk, outdoor recreation, identity

"Well, a couple days ago. We had a horrible experience on the Escalante, bushwhacking up one of the canyons. Just hideous, just the worst. I mean, my legs are just thrashed. That was terrible. But the usual." After descriptors such as "hideous," "the worst," "terrible," and "thrashed," most people would not want to make this their "usual." For many outdoor recreators, though, these are things that they learn to live with. But why? Why do they continue to engage in practices that produce these results? I contend that such practices become an enjoyable part of the experience and construct identities and, in part, this subculture. Although not all outdoor recreators adopt this view of recreation, this quote from a participant in my research about outdoor recreation demonstrates a dedication to rhetorical practices whose specific purpose is to compel a person to cope in a tough situation.

While outdoor recreation involves many activities, what I term contrived making do does not apply to all of them. For example, comfortable walks along familiar paths for short periods of time would not usually require one to make do. Dangers are possible on hikes such as this, but they are not expected nor expressly sought after. Equally, though, this analysis does not focus solely on the markedly dangerous versions of outdoor recreation such as kayaking in class five rapids, jumping out of a helicopter to ski down a mountain, and repelling through unexplored caves, where we might expect to find such practices. Instead, I found this impulse toward willing 
vulnerability manifest in many recreators I observed and participants I interviewed who expected most outdoor recreation activities to involve hardship and discomfort as a matter of course, necessitating a degree of risk tolerance and a readiness to make do. Seeking out these opportunities defines what I mean by contrived making do. In particular, this term refers to creating or seeking out situations that necessitate getting by in a physical and/or cultural sense, implying both difficult circumstances and the creativity and wherewithal to figure out improvised solutions. Recreators use this rhetorical practice to construct individual identities and parts of a broader outdoor recreation subculture and fits into a growing cultural fascination with survival, especially in the "wild."

With the rise of reality TV shows such as Survivorman; Get Out Alive with Bear Grylls; Naked and Afraid; Naked Castaway; Dude, You're Screwed; and Man vs. Wild and competitions such as the Tough Mudder and Death Race, it is worth identifying and analyzing an increasing desire in American culture that seeks out opportunities to test the limits of one's body and mind (or at least to watch others do it). These experiences might be called "desired risk" because they attract rather than repel (Machlis and Rosa, 1990). For those who want to be challenged and negotiate uncontrollable elements, outdoor recreation presents an opportunity to engage in a rhetorical practice that puts this impulse into action. Senda-Cook (2012) defines practices as "mundane, embodied, and repetitive actions; they are the daily arguments and compromises that compellingly convince us of who we are and how we ought to act" and illustrates that they can be used to demonstrate one's identity and membership to a particular subculture (p. 131). In this situation, the rhetorical practice of contrived making do has a dualistic nature. On one hand, recreators must concede some of their control, which forces them to make do. On the other hand, they do so not only willingly but also contentiously, sometimes spending hundreds of dollars to hike a specific trail or dedicating precious time off to living without the basic comforts of modern life in the US, which indicates the contrived nature. Those who participate choose the circumstances under which they must "survive," but they cannot control everything. The element of wildness and unpredictability is ever present in outdoor recreation. Simultaneously, contrived making do provides evidence of the toughness-mental and physical-of the people seeking out these kinds of experiences.

I argue that contrived making do functions as a rhetorical practice that constructs identities and parts of the outdoor recreation subculture. Making do, in this context, depends on privilege, risk-the willingness to take normalized risks and framing risk in culturally expected ways-and voluntarily surrendering some control. I start this essay by fleshing out de Certeau's (1984) concept of making do and tracing research about risk and its functions. I then discuss how three rhetorical practices embedded in contrived making do-controlling the controllable, walking the edge, and reframing the experienceevince both the actions that recreators take in the moment and the ways they talk about those experiences later. These strategies construct recreators' identities and contribute to a sense of what outdoor recreation is. This analysis adds nuance and richness to
Michel de Certeau's concept of making do. Whereas de Certeau conceptualized making do as a coping mechanism for marginalized groups, my project illuminates the role that risk plays in making do by showing how a comparatively privileged group of people seek out such experiences. In doing so, this study builds on environmental communication scholarship about risk by demonstrating that mere carelessness may not be the only source of injuries in national parks. Specifically, by focusing on visitors at a national park, this study responds to Rickard's (2014) call to document non-Nation Park Service personnel's perspectives about risk and reveals some of the complexities of this subculture that invite risky practices, understood through a framework of making do.

\section{CONTRIVED MAKING DO}

Before further discussing contrived making do, especially as it manifests in outdoor recreation, I outline the concept making do. de Certeau's (1984) contends that practices of making do are ways for people to get by in a society in which they feel they do not belong or in which they are denied privileges. For example, marginalized groups of immigrants may have to learn a new language and adapt to a new way of living while holding on to culturally important relationships and values. De Certeau states, "By an art of being in between, [they] draw unexpected results from [their] situation" (p. 30). Such actions allow people to take the conditions under which they live and "make something else out of them" (p. 32). Other scholars use making do in this way, articulating it as a way for oppressed people to subvert a problematic system (e.g., Duff, 2007; Arthos, 2013).

Making do, then, functions as resistance, a way of undermining dominant structures and gaining power at the expense of oppressors. However, Dezeuze (2008) counters that making do signals an acceptance of the status quo because marginalized people devise ways to exist within an oppressive society rather than fighting overtly to change it. Extending this claim, Josephides (1999) argues that making do fails to produce radical social change and that agents of change must go further if they want to remake society. Along this continuum of interpretation, making do represents various levels of power and agency that depend on the identities of the people and the circumstances in which they operate. Whether a form of resistance, acquiescence, or somewhere in between, making do refers to the power denied to some groups of people and their efforts, abilities, and desires to disrupt power systems.

Indeed, when he distinguishes between strategies and tactics, de Certeau aligns making do with tactics because tactics indicate less structured, more informal manifestations of power. The primary difference between strategies and tactics for de Certeau is the locus of power. Whereas strategies come from a centralized, organized source of power, tactics originate ad hoc and from individualized, disconnected sources. In his words, "Tactic is the art of the weak" (de Certeau, 1984: p. 39). Without an institutionalized power structure supporting their efforts, "displaced, disenfranchised, and dominated people" deploy tactics to make do, improvising, getting by, and carving out cultural space (Conquergood, 1992: p. 83), but, while Gallagher 
(2008) agrees that tactics are the inventive art of making do, he challenges the model of power as a zero-sum game; that is, power that is given must be seized from someone else. Instead, he advocates for an understanding based on "webs of power relations" (p. 143), which emphasizes how power reaches and generates from many different sources, overlapping and connecting unexpectedly. This metaphor of power is useful for theorizing making do because it exposes both the strength and vulnerability present within individuals and communities that can emerge under different circumstances. For example, Reed-Danahay (1993) explains that the community of rural French farmers she studied avoided direct confrontation with powerful government officials and exercised their own power in subtle ways such as failing to report that a broken public telephone (the state owned the telephone company) was allowing everyone to make phone calls for free.

Although making do implies sly ways of exercising what (small) power one possesses, it also connotes generative, creative practices. As a way to discuss these qualities of making do, scholars articulate making do in relation to bricolage and débrouillardise. Bricolage means, "ways of doing and making, ways of making do" (Duvall, 1997: p. 693). According to Kimball (2006) (pp. 71-72), "Bricolage is often translated as 'making-do,' a meaty pun on this combination of making and doing what you can with what you have." "Bricolage," in France, is associated with construction in a do-it-yourself sense. For example, "J'aime bricolage," means, "I like to putter around with things/work with things/do projects around the house." "Bricoler [the verb form] une solution" might mean "to cobble together or construct a solution." In articulating making do, bricolage contributes a sense of improvisation, self-reliance, and confidence in spite of inadequate equipment and materials.

Similarly, Reed-Danahay (1993) aligns making do with débrouillardise, which means, "the ability to be resourceful, clever, or cunning in difficult situations. This ability is primarily associated with both defensive postures toward outside threats (either natural or human) and coping strategies in everyday life" (224). For example, "Je me débrouillerai" means "I'll manage" or "I can handle it." And, in France, "Le Système D," D referring to débrouillardise, is a fairly common expression that one might use when one has to do a difficult task but is not really sure how to approach it. If someone said they are going to use Le systeme D, they would be saying, "I'll figure things out and work my way through it." It describes a flexible and creative way of problem solving and is regarded as a strength. As Houston (2007) (p. 99) notes, making do is "an act of creation using any available resources," which can range from acts of liberation to ones of practicality. Reed-Danahay claims that débrouillardise can be deployed by both weak and strong, official and unofficial individuals, echoing Gallagher's metaphor of the webs of power.

To summarize, making do itself implies power, construction, and resourcefulness. As a manifestation of power, making do is embedded with the tactics people employ to resist oppression and advance what power they possess. When people exercise bricolage, they construct solutions with limited materials, both literally and figuratively. And, finally, through débrouillardise, people take advantage of the resources available to them, finding fissures to exploit and repurposing situations, qualities, and equipment as needed to thrive physically and culturally.

By anchoring my analysis of outdoor recreation practices to the concept of making do, I am highlighting the extant nuances of this term and adding to the conversation the understanding that making do has both material and cultural elements to it and that it depends, conceptually, on risk and vice versa. Like the farmers Reed-Danahay studied, outdoor recreators need to make do in a physical sense. The ability to do so is a point of identification in the outdoor recreation subculture. Therefore, making do physically becomes a way of cohering culturally before, during, and after intense outdoor recreation experiences. Successfully making do in tough situations and narrating the story afterward, equally, construct identities for outdoor recreators individually and culturally.

What distinguishes some outdoor recreators from other groups of people who make do is that some outdoor recreators seek out or create situations that necessitate making do. Thus, I differentiate between making do and contrived making do. Regardless of their level of power outside the recreation experience, recreators pursue chances to experience disadvantaged circumstances. Privilege in this case study is not cut and dried, which is one reason I am cautious to say "some" as a qualifier of "outdoor recreators." Some outdoor recreators have large amounts of disposable income, but conversely several participants with whom I spoke explained that their families could not afford vacations in hotels, and that camping and hiking were cheaper options. And, yet, they would need to have jobs with vacation time built in, a privilege in and of itself. Therefore, while outdoor recreation depends on some privileges, contrived making do still means going without some luxuries (what some might even call basic needs such as running water). People who choose this, then, occupy a position from which they can do so. They intentionally set out for days, carrying only what will fit into a backpack; they endure cold water, insect bites, hunger, and fear simply for the experience. They give the view, the solitude, and the self-satisfaction as reasons for situating themselves in such conditions. Nevertheless, they incorporate risks in to their lives when they do not have to. To have the opportunities to make do, outdoor recreators must take risks. Abstracting this out to other groups of people who make do, it follows that making do conceptually depends on risk. Without risk, making do would not be essential to some people's lives. And, if risks are significant enough, they necessitate making do, which I discuss further in the implications section of this essay.

\section{RISK: EDGEWORK AND IDENTITY}

Almost all outdoor recreation involves some kind of voluntary risk-taking (Rickard, 2014). People willingly engage in these risky behaviors, deriving pleasure from "seeking control over the seemingly uncontrollable" (Lyng and Matthews, 2007: p. 89). Lupton (1999) (p. 157) explains risk offers "ways of adding thrills to life, testing one's boundaries of fear and endurance, proving one's adulthood or masculinity." In her research, risk is rewarding because "Transcending everyday life becomes an end and purpose in itself” (p. 157). Participants in a study about skateboarding 
described "the joys of taking risks" as their reasons for engaging in such an activity (Young and Dallaire, 2008: p. 240). Furthermore, those who pursue desired risk perceive themselves as responsible or able to handle it (Machlis and Rosa, 1990; Young and Dallaire, 2008; Davidson, 2012). When engaging in risky behaviors, participants struggle with a loss of control over some elements and come to rely on the control they have over their bodies, skills, and preparedness to escape danger. For example, "Experienced skydivers, are typically only anxious on the ascent, as plane takeoffs (the most dangerous aspect of flight) are when these skydivers feel they have no control" (Celsi et al., 1993: p. 8). In other words, they voluntarily surrender some power to test the extent of their self-control.

\section{Edgework}

Lyng and Matthews (2007) call this play between control and loss of control edgework. They explain, "Edgework is best regarded as a fully embodied practice in which the 'mind' ... is extinguished by the demand for an 'instinctive' bodily response to saving oneself" (p. 87). They adopt an edgework approach to understand why people engage in high-risk behaviors and why there has been an increase in recent times. The edgework model purports that people are drawn to risky behaviors to get a particular experience and can be prompted by the material environment. For example, people who normally would not take a risk will do so in a national park because they think it will produce the desired experience (Bickerstaff, 2004; Senda-Cook, 2012, 2013; Rickard, 2014). Lyng and Matthews explain "This seductive power derives from the attraction of a clear and vitally consequential boundary line-an 'edge,' as it were-which must be negotiated by the individual risk taker. In the purest expression of edgework, one 'negotiates' the edge by striving to get as close to it as possible without actually crossing it" (p. 78). The desire to challenge one's self with unbendable, material reality is part of what draws people to engage in risks associated with these interactions. For those who seek to test themselves by engaging in edgework, acculturating to risk, learning to live with and even enjoy it, is expected.

In outdoor recreation, participants normalize risk and pride themselves on managing it. Celsi et al. (1993) call this process risk acculturation. This is necessary in high-risk activities. Without building up a threshold of risk expectation, people would not engage in these behaviors repeatedly. Moreover, recreators need to be able to differentiate between acceptable and dangerous risks, demonstrating their phronesis. Taking unnecessary risks may be part of risk acculturation, building up risk tolerance and knowledge of how to control what can be controlled in the aftermath of such risks. Being confident that they can handle whatever risks occur encourages people to engage in contrived making do through inherently risky recreation.

\section{Identity}

For outdoor recreators, making do means correctly interpreting situations to survive even in the face of uncontrollable natural elements. Nature, especially weather, is capricious and dangerous, at times. For some people, the ability to walk to the edge (metaphorically and literally, in some cases) between success and disaster, confront their fears or push their boundaries, and, then, do it again, is crucial to their understanding of their identity. For example, Messner (1992) found that even when faced with physical pain or injury many participants will continue playing a sport or doing an activity to maintain their sense of self and outward persona. As Connell (1995) (p. 58) states, "Bodies cannot be understood as a neutral medium of social practice. Their materiality matters. They will do certain things and not others." However, athletes and outdoor recreators alike sometimes push their bodies beyond their limits for both external and internal rewards. The rewards can be the reactions of other people, the view or solitude they acquire, or the feelings and affirmations of self they receive. For example, Atkinson (2008) reports that the triathletes he studies derive pleasure from suffering through the hard training. He argues, "For many triathletes, it seems, the ability to physically endure de-routinises the drudgery of banal and disconnected everyday life" (303). In other words, controlling the body to push it beyond its normal limits is a reward in itself.

Furthering the connection to personal identity and cultural distinction, contrived making do through risky behaviors functions as a means of articulating a community of people who share values and perceptions of risk and making do. While interpretation of risk and the desire for risk alone do not define the outdoor recreation subculture, they do emphasize a salient characteristic that impacts both membership and in-the-moment choices (Tansey and O'Riordan, 1999; Bickerstaff et al., 2006; Masuda and Garvin, 2006; Baxter, 2009; Kahan et al., 2009). Contrived making do can also provide a way of resisting what members of this subculture see as a dominant culture that promotes a sedentary life and pleasures gained only through new products, objects outside the self. Crawford (2009) (p. 65) references the large cultural trends apparent in TV shows such as Survivor Man, which offer glimpses into situations of contrived making do, when he purports that working with one's hands, developing mechanical knowledge, and becoming accustomed to the "intractable nature of unchangeable systems" provide antidotes to an ontology based on immediate gratification. Additionally, Michael Atkinson (2008) (p. 307) contends that his participants saw their actions as a response to the "broader culture [that] encourages immobility and acquiescence." While dismantling this complex system seems impossible, recreators can still exercise control over their own bodies and seek ways to construct solutions with limited resources. In other words, they can make do in response to risks as a way to articulate their identity as part of the outdoor recreation subculture.

\section{CONTRIVED MAKING DO AS RHETORICAL PRACTICE IN OUTDOOR RECREATION}

Using a participatory critical rhetoric approach, I found that contrived making do functions as a rhetorical practice in outdoor recreation with three embedded practices evincing the means by which recreators articulate their identities and a subculture (Middleton et al., 2015). Participatory critical rhetoric is a research practice that necessitates the critic's participation in 
an activity, producing field notes and usually accompanied by interviewing. From novices to experts, recreators I interviewed consistently reported some common outdoor recreation practices to indicate their experiential expectations; I also observed these practices in situ during my fieldwork. After securing IRB exempt status, I spent a month conducting in situ research and interviews at Zion National Park in May and June of 2009, following all relevant IRB protocols. Specifically, I studied the fieldnotes I produced through participant observation, the 20 anonymous interviews ranged in length from about $10 \mathrm{~min}$ to over an hour and the results of an online questionnaire to which 70 people responded. At Zion, I interviewed people in a variety of locations (e.g., "frontcountry" trails, "backcountry" trails, near the snack bar, in the town adjacent to the park, and at campgrounds) and, thus, had a variety of experience levels represented. These interviews produced over 200 pages of transcripts. I engaged in open coding to identify prominent themes and developed a coding scheme. In doing so, I discovered patterns in the ways that people discuss and interact with the natural world through outdoor recreation.

Among many outdoor recreators, even those new to it, making do is part of the attraction, as is apparent in both their actions and their descriptions of those actions. Kimball (2006) (p. 72) argues that practices can "operate in material and in linguistic and rhetorical terms," which means that both observations of behaviors and talk about those behaviors should be considered in analysis. The intermingling of recreators' bodies and behaviors with the material world around them and the discourse about their experiences and expectations for themselves and others perpetuate a perception of outdoor recreation as inherently risky. The participants in this study engaged in the rhetorical practice of contrived making do even when it seemed oppositional to their stated goals (e.g., relaxing), adding to the complexity of this practice. Acts of making do range from using stones as hammers to pound tent stakes to jerryrigging ropes while canyoneering in the backcountry to using sticks as splints on a broken leg. Most people who have camped have probably experienced some version of the first example. For those who recreate frequently, the latter two examples are always a possibility. And, nearly everyone with whom I spoke had a story about getting lost or caught in the rain, being made miserable with minor injuries amplified through overuse, running out of water or food, and battling with bugs for sanity. But, three commonalities of embedded practices emergedcontrolling the controllable, walking the edge, and reframing the experience-which manifest to different degrees in most recreation. In embodying these actions and retelling them, the participants in my study constructed themselves as resourceful and aligned them with the outdoor recreation subculture.

\section{Controlling the Controllable}

The nature of contrived making do rests on surrendering control, which produces hardships to overcome by highly controlling whatever can be controlled; that is, recreators voluntarily surrender some power to elements outside their control, in this case, natural elements. Successfully balancing control ensures that recreators will be able to continue an activity. Always, in outdoor recreation, there are elements that cannot be controlled such as weather and wildlife, which is part of the attraction to outdoor recreation. Contrarily, recreators come with elements they can control: equipment, knowledge, physical fitness, and their state of mind. In particular, interviewees mentioned that before engaging in outdoor recreation activities, participants should expect to have to make do in difficult situations, to engage in a bricolage or Le Système D. In recreation activities, recreators test themselves by taking advantage of those elements they can control and correctly interpreting those they cannot. This embedded practice manifested in the ways that people negotiated encounters when elements slip out of their control. Most participants expressed strong feelings of personal responsibility, which prompted them to make prudent decisions. However, because the nature of the activities is risky and the purpose many times is to reach a specific destination, many recreators articulate their identities through their ability to endure the risks and achieve the goal, which in turn defines parts of the outdoor recreation subculture.

One common theme was the acknowledgment that one should stop engaging in recreation activities when one is starting to lose control through fatigue, bad weather, dwindling supplies, or an injury. One interviewee said she stops hiking, "At the point where you're tired enough that you won't be able to get back safely if you don't turn around." In other words, while they still have things under control, if they feel themselves slipping, it is better to make responsible decisions for their own safety and the safety of others. One person said "If the weather's bad and it gets dangerous, you turn around. Do the right thing and go back, call it over." For these participants, they frame themselves as in control and state openly that it is important to accurately assess risk and respond responsibly. One woman said, "I just try to not-not to get too far from what I know is a safety zone 'cause I know I wouldn't want to put myself in danger nor would I want to put anyone else in danger coming to rescue me." These comments illustrate that recreators know they are facing some inherent but tolerable risks in outdoor recreation, but that they want to control the elements they can to minimize this danger. If they see people who make bad choices and get in trouble, they understand that the uncontrollable elements have become out of balance. When that happens, danger increases.

One participant described a situation in which he got stuck in a snowstorm while climbing a mountain and had to hang from his ropes for hours. He said he knew he might die and had to reflect on how he got into that dangerous situation. In this quote, he explains the source of many problems in outdoor recreation:

Obviously, I think probably similar to most people, bad experiences outdoors are often related to weather and, um, of course, you could have a bad experience if you were not smart enough and made personal decisions that were foolish and-But luckily, we've been fairly good at knowing the right thing to do. So then it boils down to the bad experiences due to factors beyond our personal control. 
This quote illustrates the balance between controllable and uncontrollable factors and points to internal and external loci of control. This participant locates control internally when he assigns blame (albeit mildly) to people who "were not smart enough and made personal decisions that were foolish." In the situation on which he was reflecting, he was counting himself among the foolish, among those who failed to correctly read the situation and respond in time to guarantee his own safety, but he also acknowledges that sometimes people can do everything right and still end up in a dangerous situation, if the locus of control is external. When he says that "the bad experiences [are] due to factors beyond our personal control," the onus lies elsewhere. This description realizes the metaphor of a web of power in which power is not a zero-sum game but rather a complex system with many pieces. The weather, the mountain, the ropes and other gear all have some power-unconscious, indifferent, material, and utterly uncontrollable. Yet, recreators also have power-conscious, invested, sometimes material, and within their control. They can look up weather reports, scout the best route, read accounts of a climb, check their gear for wear and choose the right gear needed, train for the activity, and be honest about their own abilities. If one of the elements of the web is out of balance (i.e., too powerful or not powerful enough), the situation can become dangerous. Part of contrived making do is flirting with the uncontrollable. Seeking out the potential for material danger out of one's control creates an opportunity to understand something about the self.

Losing and gaining control thrills some recreators and doing well in these situations can positively impact their identities. As Lupton (1999) (p. 160) states, "To engage in dangerous activities, for example, may demonstrate a man's [sic] control over the emotions of fear, vulnerability and anxiety, proving to others and himself the expanded limits of his [sic] control of self and the body. At the same time it affords him [sic] the opportunity to experience and enjoy heightened emotion and exhilaration." Controlling emotions and personal choices about when to go rock climbing, what to take, and how to train all factor into a successful recreation trip. Preparing as best as one can for the uncontrollable (and perhaps the unforeseeable) is a practice that recreators value and connect with their own identity and that of others (Senda-Cook, 2012). For example, one man echoed the concerns that others expressed about putting other people in danger if they got lost or hurt. He said that if a person picks a difficult hike on a bad weather day, "You're putting yourself at risk. If you get stuck and call out, then people are going to try to help you." And, his wife continued this line of thought and extended it to the identity implications of having to be rescued. She said, "Yeah, and I'd feel a right idiot if I had to call out mountain rescue. It feels, I don't know. I'd be quite humiliated, really." Although recreators desire this struggle for control, they do not actually want to get hurt, stranded, or lost, and they do not want to put other people at risk. Therefore, among recreators, it is important to know when to quit.

And, yet, when recreators exercise their control, they continually choose to carry on. During my fieldwork on trails, I saw over and over people going on despite their fears, their fatigue, their inexperience, their inadequate equipment, the bad weather, and the warnings of the National Park Service. People wanted to be able to say that they hiked a certain trail; for some, they wanted the experience of hiking the trail (whether they ever told anyone or not); some people did not want to lose face among their companions or be left behind by them. For many reasons relating to their understanding of themselves as people, they chose to push to the end of Angels Landing, even though they were afraid, wade through the Narrows despite flash flood warnings, and climb over boulders to catch up to the rest of their group walking up Hidden Canyon. Some interviewees acknowledged that they would not feel good about themselves if, when they could control the situation, they decided to quit. One person said, "I mean, if I thought it was an easy trail, and I, you know, if I thought it was a trail I could have made, [I would feel] a little disappointed [if I didn't finish]." But this person added, "If I get onto a trail and I really feel like it's dangerous or it was more than I really wanted to take on, I'm fine with [turning around]." Recreators, in their words, acknowledge that it is acceptable and desirable to stop if the situation is out of their control. However, recreators appear reluctant to turn around if it is a matter of controlling their own bodies. On the trail, I witnessed many people failing to recognize danger and continuing on. For them, seeing dozens of people hiking blithely onward makes it difficult to determine if they are losing control and should turn around.

The outdoor recreation subculture urges this consciousness of control. In talking with participants, their stories of bad experiences and reasons for ending a hike revealed the struggle associated with the practice of balancing control. Additionally, when they frame themselves as able to endure uncontrollable forces, they at once account for why something bad happened and emphasize that people with correct knowledge and experience make good choices and are able to successfully make do. In articulating when it is acceptable to turn around, one participant was analyzing her own behaviors and those of her companion: "Maybe if it's for reasons of safety and for your own health, then I think it's completely fine [to turn around]. Because you [to her companion] weren't happy, but you were OK. You were still, like, able to go on. But if you were concerned you wouldn't be able to make it back, then I think that's fine." Controlling one's emotions is an expected part of the outdoor recreation subculture. Even if someone is unhappy, they are expected to continue on the hike because they are not in danger. People learn that if they balance control appropriately, their choices will be interpreted by others as simultaneously prudent but not cowardly.

Knowing when one is in still control is critical for activities such as backpacking where, to end a hike early means calling out Search and Rescue. In contriving a situation for making do, recreators select how difficult they want to make the activity. If they choose to pack everything they think they will need into a backpack to hike and camp for a few days, then they are choosing a situation that requires them to control everything they can and simply endure what they cannot control. As one participant describes:

I was on that backpacking trip, where you have, like, a 100 -pound pack on. That was, like, some of the most 
pain and misery I've been in, but I still went on because I wanted to finish that trip. Oh, and you sort of had to, too. [laughing] If you stopped, you'd be in the middle of nowhere.

In this type of contrived making do, controlling the controllable means training, packing correctly, and physically and mentally withstanding the "pain and misery." Even if every other uncontrollable element goes smoothly, as planned, this kind of trip will be difficult, which is part of the attraction to outdoor recreation. Although this type of attitude reflects this individual's identity, it is also part of the outdoor recreation subculture, which comprised people who seek out challenging experiences that will require them to control, above all else, themselves and accurately determine when to continue and when to stop.

\section{Walking the Edge}

On the trail and in conversation, experts and novices alike recognize that outdoor recreation necessitates discomforts and some risks, which must be tolerated, if not embraced. Knowing that one must continue an activity in the face of hardships requires recreators to approach the line between discomfort and danger, meaning that recreators must walk along the edge between the two. Doing so is a part of contrived making do because it demonstrates that recreators are comfortable with situations that produce discomforts and come with risks, which then becomes part of one's identity and the values of the outdoor recreation subculture.

Persisting through discomfort is a part of outdoor recreation as evidenced on trails themselves. Personally, I have experienced the range of ordinary discomforts and minor injuries that come with recreating outdoors (e.g., blisters, sunburns, dehydration, overheating, insect bites, abrasions, altitude sickness, and strained muscles). Additionally, I observed people hiking in spite of these kinds of mild problems, revealed by their wearing braces and bandages. Passing by people sitting on rocks to dress wounds or take a break, I would see them later on at the end of the trail or on the return trip. I overheard conversations in which people planned what hikes to do on that day, considering the fatigue or injuries incurred on the previous day. In an interview, one couple made it plain. They spoke of "necessary discomforts" while we were talking, and I asked them to elaborate on that. They explained:

Participant 1: Well, you're going to be cold at times. You're feet are going to be tired.

Participant 2: Or you're going to be hot.

P1: You're going to be hot, yeah. Yeah.

P2: You might not always feel pristine clean either.

P1: $\quad$ Exactly. Yeah. Yeah, I've had some very miserable times when I was outside. But it was, it was part of it. I mean it's not like it was a-I've never-I've been fortunate and I've never been in a survivor, a real survivor situation. But, um, yeah, there are some uncomfortable times associated with doing anything outdoors.
This person distinguishes between "real survivor situations" and discomforts, giving voice to the experience of walking the edge. Most of the participants in my study acknowledged that even if they did not have to endure high-risk situations, good recreation meant physically and emotionally challenging themselves, living with minor pain at times. People wanted to feel as if they had a "good workout"; they liked to feel the soreness of their muscles. Some people explicitly stated that they liked being away from modern conveniences (a form of making do itself). One participant called it a "voluntary regression in lifestyle." While persevering through discomforts and overcoming minor risks can be rewarding because it gives people opportunities to grow, as the previous practice described earlier has shown, recreators generally try to avoid dangerous situations.

Selecting some recreation activities over others give recreators the opportunity to display their comfort with the edge between discomfort and danger. By choosing more intense activities, they create situations to test themselves, feeling out the boundary between making do in uncomfortable times and simply making dangerous choices. For example, I observed hundreds of people with all different skill levels hiking the most popular trail in Zion National Park, Angels Landing. With its 1000-foot cliffs and slippery sandstone, this trail has inherent risks. However, if visitors want to see this view, they must acculturate to these risks and become comfortable enough to make it to the end of the busy trail and back. And many visitors-even people with little hiking experience-do. In this way, recreation functions as a proving ground for one's body and mind because participants understand that risk is itself both part of the activity and part of the reward. One participant stated it well, "We've gotten into some tight spots occasionally. But we've always got out of it. So, it's all part of the fun of it, really." This quote is a good example of relationship between contrived making do and risk acculturation that occurs in outdoor recreation. These interviewees know that they will encounter problems and will have to solve them to get home safely. Knowing these dangers exist even if they do not happen every time someone recreates, means that people must be accustomed to walking the edge. The feelings that accompany this embedded practice are part of the pleasure of risk-taking, in general, and outdoor recreation, in particular.

If people engage in practices of contrived making do to learn something about themselves or exhibit their identities, then they must learn to distinguish between discomforts and dangers. To walk the edge, they must be able to, at least roughly, locate the edge. And, doing so, makes subtle claims about their nature, their strengths and weaknesses. One participant explained, "I think I would feel pretty bad if I did not finish the actual trail. I thought of turning around [during a difficult hike], but I thought it would be awful to turn around just because I was tired." Putting up with the discomfort of fatigue becomes part of this person's sense of self. Moreover, many people would tell stories or explain conditions that they have hiked through that sounded truly awful. For example, one couple recounted how they almost got hypothermia and another man reported that getting thrown off horses was a normal part of riding them. 
When I asked if it stopped them from engaging in those activities, they responded "Oh, definitely not," as one interviewee put it. During an interview with a group of students visiting a series of national parks, a few of their comments revealed not only how they were learning to locate the edge but also about how doing so communicated an identity:

Participant 1: When I turned around, I ended up being kind of disappointed in myself because I just stopped because my feet hurt and I was tired. Like, it just wasn't fun anymore. But then I had to sit at the campsite alone in 100 degree heat and not have anything to do. So, I ended up feeling very disappointed in myself that I didn't keep going and, like, push on through it and accomplish something.

Participant 2: I mean. Yeah, I guess. Cause, yeah, even when we were on the Canyonlands trip. It was like the second day-I mean looking back at it now, I really enjoyed it-but at the time, I was like miserable -

Participant 3: Miserable. The last mile was just so painful, but you didn't have a choice. It wasn't like you could just give up and sleep there for the night.

This conversation demonstrates how people develop risk acculturation of outdoor recreation. The first participant explains that early on, she was in pain and turned around while the rest of the group continued hiking and she ended up being disappointed in herself. Seeing other people do it and hearing how they talked about it had taught her that her level of pain and frustration was normal and expected. The other two participants talk of being "miserable," but they acknowledge that they had to make it back to camp. This is the crux of the difference between discomfort and danger in outdoor recreation. Being able to make this distinction allows outdoor recreators to forego some of their control and gives them an opportunity to make do. In such situations of contrived making do, recreators cannot give up without calling out Search and Rescue. Therefore, short of an emergency, they learn to push through the pain.

The outdoor recreation subculture frames outdoor recreation as inherently risky and some parts of it embrace this risk through contrived making do. As a result, it can be difficult to determine how much danger is acceptable, which is especially true when personal pride is involved, as some of the comments above illustrate. However, another key part of the outdoor recreation subculture is the reward for walking the edge. Many interviewees discuss the accomplishment they feel after they have made it through a risky situation, the prize of solitude they receive when they make it to a beloved out-of-the-way spot, or the power of the perspective they acquire when viewing the world from the edge of a cliff to which they have just hiked. When I asked about what made a trip especially good or what they liked about recreating, people responded: "Um, probably the feat, the intensity, kind of the accomplishment"; "It's totally a payoff"; "A sense of accomplishment"; "Once you get to the top, totally worth it. A lot of work to get there, but gorgeous once you're there." One respondent said, "Yeah, I found [the top of a mountain] terrifying because there was so much wind. And, it was just amazing to see these national monuments, even if it was terrifying at times. [laughs]" These participants tout overcoming fear and pain by talking about the rewards that they get for doing so. This not only helps them accept the discomforts and dangers of outdoor recreation, it also reframes experiences to fit into typical discourses about outdoor recreation.

\section{Reframing the Experience}

Showing fear at the moment of engaging in a risky behavior is fairly common in outdoor recreation. By contrast, in recounting those experiences, recreators rarely relive the fear they experienced and tend to laugh as they tell the stories. Some participants simply deny having bad experiences. In others, laughing it off displaces representations of fear with humor. Reframing bad experiences through denial and humor to cover for fear are ways of coping with discomfort, risk, and pain and renders making do (contrived and otherwise) ordinary and containable. Additionally, the discourses generated through this practice position recreators as tough or at least willing to continue, which has a coalescing function for parts of the outdoor recreation subculture.

When I asked participants about their worst experiences recreating, most would either say that they had never had a bad experience (even if by most standards, they had) or they would laugh about their bad experiences. In response to this question, one couple both denied having the bad experience and then laughed about it:

Participant 1: I don't know. It would be hard to say. Was there anything-were there any that were all that-?

Participant 2: I don't know. That one camping trip that got kind of rained out almost the entire time. That was-[laughs].

P1: $\quad$ Was that one of the Trout Creek ones?

P2: $\quad$ That was when we were out with the church group. Remember we had to put everything back in the car all wet?

P1: Oh. [laughs] I don't know. I think I've kind of blocked a lot of that out of my mind.

P2: When you can't enjoy anything because it rains the whole weekend and you have to put everything back in the car all wet. And, it makes a mess when you get home, yeah, that can put a damper on things.

P1: $\quad$ Oh, right. The one where we had cords strung all over the garage so we could hang up the tents and the sleeping bags. Yeah, OK, yeah, that one was, yeah. I guess that's as close as you can say to "the worst." We still had fun, but it was a lot of hassle.

First, these participants cannot recall a bad experience. Then, once they do, they laugh. And eventually, P1 ends up saying they still had fun. Deriving pleasure from even the bad experiences is critical because part of the point of contrived making do is to engage in these uncomfortable-and risky-situations. One 
interviewee, after describing a climbing trip during, which he and his partner forgot a second rope and had to jump or free climb to a ledge 10 feet below where their rope ended, said, "You know, when I think back, I don't remember anything that I would not want to do again. There's probably stuff I wouldn't want to do again as far as a certain trail or something, but I've generally enjoyed most of my trips." Another couple remarked simply, "We never have a bad time when we're outside." Then, one of them elaborated,

You know actually we've had some-I've had some fiascoes at different points in time, but, ah, I think I've enjoyed them all. Even the bad times. I think I've just enjoyed being out. And, you know, the good comes with the bad. You have to put up with both of them.

Another couple recalled a time when they were lost on a mountain in fog and could not find the trail. They estimated that they went five to six miles off the trail and spent hours longer hiking than they had intended. At the end of this story, they concluded, "But in the end, it was a really good, fun day. We've never really had a bad walk ever." This reframing of bad experiences as good indicates that these folks have acculturated thoroughly to the realities of outdoor recreation and continue to seek out contrived making do and desired risk. Not only do they understand that risks exist, they expect them and interpret them as a part of having a good time, which makes identifying a bad experience more difficult.

In some of these responses, participants acknowledge that they had a bad experience but laugh about them. In one interview, I commented on the interviewee's nonverbal messages (e.g., looking at the ceiling, laughing, and hesitating) that accompanied what he said:

Participant: [laughs] Ah, let's see. Going down in the Grand Canyon by Lee's Ferry? There was a-I don't know if it's a real popular trail. I don't think it is. But we found this trail that goes, like, straight down and straight back up, didn't bring enough water, and it was brutal. It was only, like, two or three miles roundtrip or something. Probably two miles, just a mile straight down and a mile up. But it was the hardest two miles I've ever climbed.

Interviewer: And so you wouldn't do that again?

P: $\quad$ Ah. No, I'd probably pick a different way down.

I: You were thinking about it, too. You were like, "maybe I would."

P: $\quad$ [laughs] Well, it was fun, too. When you got down to the bottom, it was amazing, you know? But when you're coming back up, you're just dying.

This participant laughed throughout the telling of this event even though this could have been a very serious situation. The Park Service rescues hundreds of people in the Grand Canyon every year because they run out of water while hiking (Shier, 2013).
When people deny that bad experiences exist and laugh them off, they are showing themselves to be comfortable with the risks they have sustained and the possibility that more will continue. Engaging in these rhetorical practices-both the recreation itself and the talk about it-positions the speaker as part of the outdoor recreation subculture-someone who resists the comforts of contemporary life-and thus as someone who is accustomed this kind of entertainment. Through these stories, the interviewees were narrators alternatively framing themselves as inept enough to forget some key piece of equipment and resourceful enough to do without it or flexible enough to make the best of camping in the rain. After all, they would explain, this is nature of outdoor recreation, and if they did not like it, they would not continue to seek out such experiences.

Therefore, in reframing their experiences and articulating their identities through this rhetorical practice, they would also define parts of the outdoor recreation subculture. One interviewee put it eloquently at the end of a story about hiking the Manchu Pitchu trail in a snow storm with severe bronchitis. She said,

I truly thought that $O K$, this is it, my health is ruined; I' $m$ really going to have serious, long-term problems with this. So, that's one of my memorable bad experiences. You know, you usually laugh about these things later. I mean, even the bushwhacking one [that happened just the day before], we're already laughing about it, and it was horrible. You know, it happens. So, stay home.

Her attitude that if people are not ready to laugh at a horrible, even a life-threatening experience, then they should stay home emphasizes the expectation that recreators ought to be willing to make do even in bad situations because that is the norm for outdoor recreation. By denying that bad experiences happen or laughing about them, outdoor recreators construct their identities and define themselves in the broader outdoor recreation culture through embedded practices like voluntarily surrendering control and struggling to gain it back and walking the edge between discomfort and danger.

Both engaging in the rhetorical practice of contrived making do and talking about it constructs individuals' identities. On the trail, so to speak, they use actions to display who they are and reinforce that identity articulation afterward by narrating the story. Outdoor recreation has risks like unpredictable nature (e.g., weather and wildlife), which render it a perfect context for contrived making do. To "keep coming back for more," as one interviewee put it, people have to have a certain tolerance, and even a desire, for uncertainty and discomfort as revealed through the embedded rhetorical practices of controlling the controllable, walking the edge, and reframing the experience. Although they do not have to push themselves to endure terrifying, windy mountaintops, hypothermia, or dehydration, these choices allow them to construct their identities as resourceful, creative, and part of the outdoor recreation subculture. 


\section{CONCLUSION AND IMPLICATIONS}

Contrived making do, as articulated through the embedded practices of controlling the controllable, walking the edge, and reframing the experience, constructs opportunities for recreators to display their identities and define parts of the outdoor recreation subculture. Specifically, some people who recreate employ these rhetorical practices to distance themselves from what they see as a culture built on convenience. In doing so, they reinforce a perception of the outdoor recreation subculture as a venue to challenge one's toughness through accepted risks, which is touted as "part of the fun." This project contributes to environmental communication scholarship by illuminating a pattern of risktaking that impacts how managers of national parks communicate with visitors about risks. The acts of making do while recreating can vary widely with some far more serious than others, but, the common threads are the presence and acceptance of risk and the privilege to choose it. In seeking out situations in which to make do, recreators must acculturate to risk, which illuminates the relationship between making do, in general, and risk.

The first implication of this analysis is that making do implies risk and pain. Although not all risk-taking involves making do, it is important to recognize the function of risk in making do. People who chose this have privilege. They may belong to any social class but they are in a position to take time off of work and have the capacity to address at least the expected injuries associated with outdoor recreation. However, studying this privileged group of people reveals some things about the making do that de Certeau describes in terms of risk tolerance and pain endurance. In de Certeau's (1984) understanding, marginalized groups use the tools of a dominant society to their own ends, creating spaces for identity and empowerment by repurposing or reclaiming practices and discourses of dominant cultures, a risky proposition in the best of times. The disempowered groups conventionally associated with making do need not seek out opportunities to test themselves because they encounter risk, endure pain, and face their fears daily. By appropriating the discourses and practices of dominant cultures, they are risking punishment, exposure, and excommunication. Risks could come from powerful external sources such as police, landlords, or employers. But they may also discover risks within their communities if other members see them as inauthentic (see, e.g., Jackson, 2005 and Johnson, 2003), complacent (see, e.g., Dezeuze, 2008), or simply ineffective (see, e.g., Josephides, 1999). These internal risks may prove more painful even than those imposed by groups in power. By making the role of risk salient in the concept of making do, this analysis also demonstrates the web of power model present in practices of making do.

As articulated in the literature review, power is a part of understanding what it means to make do. If we consider power in terms Gallagher's metaphor of a web containing both strategies and tactics, we can imagine that a variety of people, organizations, and elements control different aspects of the web. In cases of disenfranchised communities, members have power over one another and under specific conditions within larger cultures. Pulling one power thread in the web has consequences for the other people present. In the case of outdoor recreation, because of its enormity and indifference, natural elements can powerfully challenge recreators even under the most predictable circumstances. But, recreators can exercise their own power by constructing survivable solutions through resourcefulness. In other words, they control what they can, which produces metaphors of power and struggle in outdoor recreation (e.g., "I conquered that mountain," "that trail was a killer," and "I got owned/schooled/ slaughtered by that trail"). They also warn others about what cannot be controlled, producing creative names of trails and features (e.g., Fat Man's Misery, Devil's Thumb/Tower/Punchbowl, and Dead Horse Point). In the face of impossibility, people struggle to gain control and look for models and advice wherever they can find them, giving power to many individuals and organizations (only some deserving).

The second implication, then, is that risk managers should be perceptive and realistic about the multiple sources recreators use for information. Environmental communication scholars Rickard et al. (2011) showed that national park visitors receive messages from many different sources about risk; my study extends this line of research by showing that the messages can also come in the form of rhetorical practices. In particular, when seasoned recreators report pushing themselves to and past their own limits but encourage others who are inexperienced to only do what they can, people who are new to recreation receive mixed messages. They see the rhetorical practices of controlling the controllable and walking the edge and hear the reframing of experience. Add to that magazine articles that recount (and somewhat celebrate) near-death experiences and TV shows purportedly depicting survival. These entities function as information sources and can powerfully shape the culture and expectations of outdoor recreation. My study adds to existing research to demonstrate how embodied, repetitive actions create parts of a subculture and a corresponding interpretive framework (Bickerstaff and Simmons, 2009).

The consequences of this framework could range along a continuum of helpful and harmful. For example, seeing other hikers' behaviors and hearing their stories could give people new to these activities a realistic expectation and help them prepare. Therefore, the embedded practices of contrived making do could negate some of the risks by encouraging people to anticipate rough weather and other dangers. However, it could also harm people by creating an expectation that they must go beyond their limits and capabilities. Every year, Search and Rescue teams risk their own lives to help people who have lost their way, become trapped in bad weather, or injured themselves. The National Park Service states in its Search and Rescue Reference Manual that it will make saving a human life a priority over everything else when needed, which makes all rescues sound dramatic. However, according to a ranger I interviewed, most rescue calls are for relatively short hikes in the frontcountry. These areas get the most visitors, which partially explains why they comprise most of the calls. I suggest, however, that the subculture of outdoor recreation is also partially to blame. By cultivating the expectation that outdoor recreation is inherently risky and an opportunity to push oneself to the limit, the subculture itself sets the stage for people to test themselves and fail, sometimes tragically. This points to a need to balance risk and draw a line 
between making do and folly. When acculturating new people to the risks of outdoor recreation, park staff and experienced recreators need to both normalize risks and teach people to avoid undesired risk, which creates a challenge for risk communicators (Rickard, 2014). All of the messages-whether they are embodied practices or verbal-become part of the interpretive framework in national parks that impacts what decisions visitors make.

Future research could analyze how embedded practices of contrived making do-occur in other arenas and trace their consequences. For example, the themes outlined in this essay exist in many kinds of sports and exercises, as scholars such as Atkinson (2008), Messner (1992), and Connell (1995) have argued. Additionally, we might see it in some professions such as police officers, firefighters (Scott and Myers, 2005), 911 operators (Tracy et al., 2006), and EMS responders. Firefighters and EMS responders also have their outdoor equivalents, Hot Shot crews and Search and Rescue teams, which communication scholars have yet to study. Both the challenge and rewards are in the risks people take to make it in these difficult, sometimes dangerous, realms. My analysis of contrived making do in the context of outdoor recreation highlights how embedded practices of making do encourage participants to choose to take risks and blur the line between acceptable risks and dangerous ones.

When recreators laugh off their almost drowning or getting lost in the desert or having their campsite disturbed by bears, they construct their own identities as able to handle such misadventure and they establish and reinforce the norms of the outdoor recreation subculture. Being "scared shitless," as one of my interviewees put it, is not enough to make someone quit. Not only do the recreators need to get through the experience, they will likely have to get over that fear to do the activity again. Contrived making do allows people to answer the current cultural impulse to experience "survival," if only in a mild sense. However, the embedded practices have additional consequences. They can prepare people for possible problems but can also raise the threshold of risk acceptance, making recreation more dangerous overall. These practices both reflect and create sensibilities about

\section{REFERENCES}

Arthos, J. (2013). The just use of propoganda (?): ethical criteria for counterhegemonic communication strategies. West. J. Commun. 77, 582-603. doi:10.1080/10570314.2013.785014

Atkinson, M. (2008). "Enduring bodies in triathlon," in Tribal Play: Subcultural Journeys through Sport, eds M. Atkinson and K. Young (Bingley, UK: JAI Press), 295-317.

Baxter, J. (2009). A quantitative assessment of the insider/outsider dimension of the cultural theory of risk and place. J. Risk Res 12, 771-791. doi:10.1080/13669870802579806

Bickerstaff, K. (2004). Risk perception research: socio-cultural perspectives on the public experience of air pollution. Environ. Int. 30, 827-840. doi:10.1016/j. envint.2003.12.001

Bickerstaff, K., and Simmons, P. (2009). Absencing/presencing risk: rethinking proximity and the experience of living with major technological hazards. Geoforum 40, 864-872. doi:10.1016/j.geoforum.2009.07.004

Bickerstaff, K., Simmons, P., and Pidgeon, N. (2006). Situating local experience of risk: peripherality, marginality and place identity in the UK foot and mouth disease crisis. Geoforum 37, 844-858. doi:10.1016/j.geoforum.2005.11.004

Celsi, R., Rose, R., and Leigh, T. (1993). An exploration of high-risk leisure consumption through skydiving. J. Consum. Res. 20, 1-23. doi:10.1086/209330

Connell, R. W. (1995). Masculinities. Berkeley: University of California Press. what it means to engage in outdoor recreation. The rhetoric that many recreators use to describe their experiences frames outdoor recreation as a rewarding struggle, creating a context in which misery is normal and even, in retrospect, enjoyable.

\section{ETHICS STATEMENT}

This study was carried out in accordance with the recommendations of the Collaborative Institutional Training Initiative and the University of Utah Institutional Review Board with written informed consent from all subjects. All subjects gave written informed consent in accordance with the Declaration of Helsinki. The protocol was approved by the University of Utah Institutional Review Board.

\section{AUTHOR CONTRIBUTIONS}

SS is the sole author of this work. Any correspondence should be directed to her.

\section{ACKNOWLEDGMENTS}

I would like to thank several people who have supported me in this project, in particular, Danielle Endres, David Vanderboegh, the editors and reviewers of this journal, the David C. Williams Memorial Graduate Fellowship, the Floyd O’Neil Scholarship in Western American Studies, and the staff of Zion National Park. Portions of this paper were presented at the Conference on Communication and the Environment in 2013 and appear in the conference proceedings.

\section{FUNDING}

The author would like to recognize the David C. Williams Memorial Grant Fellowship that helped facilitate this work and the Floyd O’Neil Scholarship in Western American Studies.

Conquergood, D. (1992). Ethnography, rhetoric, and performance. Q. J. Speech 78, 80-97. doi:10.1080/00335639209383982

Crawford, M. (2009). Shop Class as Soulcraft: An Inquiry into the Value of Work. New York: Penguin Press.

Davidson, L. (2012). The calculable and the incalculable: narratives of safety and danger in the mountains. Leisure Sci. 34, 298-313. doi:10.1080/01490400. 2012.687617

de Certeau, M. (1984). The Practice of Everyday Life. Berkeley: University of California Press.

Dezeuze, A. (2008). Assemblage, bricolage, and the practice of everyday life. Art J. 67, 31-37. doi:10.1080/00043249.2008.10791292

Duff, C. (2007). Towards a theory of drug use contexts: space, embodiment and practice. Addict. Res. Theory 15, 503-519. doi:10.1080/ 16066350601165448

Duvall, W. (1997). Are we postinterruption? Postmodernism, resistance, and practice. Eur. Legacy 2, 690-696. doi:10.1080/10848779708579796

Gallagher, M. (2008). "Power is not an evil": rethinking power in participatory methods. Child. Geograph. 6, 137-150. doi:10.1080/14733280801963045

Houston, L. M. (2007). "Making do": caribbean foodways and the economics of postcolonial literary culture. Multi Ethn. Lit. 32, 99-113. doi:10.1093/ melus/32.4.99

Jackson, J. Jr. (2005). Real Black: Adventures in Racial Sincerity. Chicago: University of Chicago Press. 
Johnson, E. P. (2003). Appropriating Blackness: Performance and the Politics of Authenticity. Durham: Duke University Press.

Josephides, L. (1999). Disengagement and desire: the tactics of everyday life. Am. Ethnol. 26, 139-159. doi:10.1525/ae.1999.26.1.139

Kahan, D. M., Braman, D., Slovic, P., Gastil, J., and Cohen, G. (2009). Cultural cognition of the risks and benefits of nanotechnology. Nat. Nanotechnol. 4, 87-90. doi:10.1038/NNANO.2008.341

Kimball, M. A. (2006). Cars, culture, and tactical technical communication. Tech. Commun. Q. 15, 67-86. doi:10.1207/s15427625tcq1501_6

Lupton, D. (1999). Risk. London: Routledge.

Lyng, S., and Matthews, R. (2007). "Risk, edgework, and masculinities," in Gendered Risks, eds K. Hannah-Moffat and P. O’Malley (New York: Routledge-Cavendish), 75-97.

Machlis, G. E., and Rosa, E. A. (1990). Desired risk: broadening the social amplification of risk Framework. Risk Anal. 10, 161-168. doi:10.1111/j.1539-6924.1990.tb01030.x

Masuda, J. R., and Garvin, T. (2006). Place, culture, and the social amplification of risk. Risk Anal. 26, 437-454. doi:10.1111/j.1539-6924.2006.00749.x

Messner, M. (1992). Power at Play: Sports and the Problem of Masculinity. Boston: Beacon Press.

Middleton, M., Hess, A., Endres, D., and Senda-Cook, S. (2015). Participatory Critical Rhetoric: Theoretical and Methodological Foundations for Studying Rhetoric In Situ. Lanham, MD: Lexington Books.

Reed-Danahay, D. (1993). Talking about resistance: ethnography and theory in rural France. Anthropol. Q. 66, 221-229. doi:10.2307/3318065

Rickard, L. (2014). Mountains and handrails: risk, meaning, and responsibility in three national parks. Environ. Commun. 8, 286-304. doi:10.1080/17524032.2013.850109

Rickard, L., McComas, K., and Newman, S. (2011). Visitor proficiency profiling and risk communication at a national park. Environ. Commun. 5, 62-82. doi:10.1080/17524032.2010.535837
Scott, C., and Myers, K. K. (2005). The socialization of emotion: learning emotion management at the fire station. J. Appl. Commun. Res. 33, 67-92. doi:10.1080/ 0090988042000318521

Senda-Cook, S. (2012). Rugged practices: embodying authenticity in outdoor recreation. Q. J. Speech 98, 129-152. doi:10.1080/00335630.2012.663500

Senda-Cook, S. (2013). Materializing tensions: how maps and trails mediate nature. Environ. Commun. 7, 355-371. doi:10.1080/17524032.2013.792854

Shier, S. (2013). Hike Smart Podcast 01 - What is PSAR? Arizona: Grand Canyon National Park. National Park Service.

Tansey, J., and O'Riordan, T. (1999). Cultural theory and risk: a review. Health Risk Soc. 1, 71-90. doi:10.1080/13698579908407008

Tracy, S. J., Myers, K. K., and Scott, C. W. (2006). Cracking jokes and crafting selves: sensemaking and identity management among human service workers. Commun. Monogr. 73, 283-308. doi:10.1080/03637750600889500

Young, A., and Dallaire, C. (2008). "Beware $\#$ ! SK8 at your own risk: the discourses of young female skateboarders," in Tribal Play: Subcultural Journeys through Sport, eds M. Atkinson and K. Young (Bingley, UK: JAI Press), 235-254.

Conflict of Interest Statement: The author declares that the research was conducted in the absence of any commercial or financial relationships that could be construed as a potential conflict of interest.

Copyright (C) 2017 Senda-Cook. This is an open-access article distributed under the terms of the Creative Commons Attribution License (CC BY). The use, distribution or reproduction in other forums is permitted, provided the original author(s) or licensor are credited and that the original publication in this journal is cited, in accordance with accepted academic practice. No use, distribution or reproduction is permitted which does not comply with these terms. 